\title{
Pendekatan Budaya Islam di Madrasah melalui Pengenalan Ilmuan Muslim al-Khazani dengan Konsep Tekanan Udara pada Pembelajaran Fisika
}

\author{
Tiana Azmi Alawiyah \\ Program Studi Pendidikan Fisika, UIN Sunan Gunung Djati Bandung \\ E-mail:tiana.azmi@gmail.com
}

\begin{abstract}
Muslim scientists create a lot of great works in the field of science but the findings of Muslims have not been applied by teachers in science learning in madrasah. One of these Muslim scholars was Al Khazini with his findings of air pressure, preceded the western scientist Blaise Pascal (1588-1651 AD). The purpose of this study to reveal that the work of Muslim scientists can be used as a source of science learning in madrasah to be culturally closer to Islam. The research method used is qualitative method by using historical approach of philosophy of science in Islamic perspective. Data were collected through literature study. The results showed that Al-Khazini is revealed about air pressure earlier than Pascal. These findings can be taught in madrasah through methods of sociologically anthropological demonstrations that close to madrasah culture.
\end{abstract}

Keywords: Philosophy of Science, Air pressure, Islamic School.

\begin{abstract}
Abstrak
IImuan-ilmuan muslim banyak menghasilkan karya-karya yang besar dibidang sains akan tetapi temuan muslim itu belum diterapkan oleh guru dalam pembelajaran IPA di madrasah. Salah satu ilmuwan muslim tersebut yaitu Al-Khazini dengan penemuannya mengenai tekanan udara, yang mendahului ilmuwan barat Blaise Pascal (1588-1651 M) dalam riset dan penemuan bahwa udara mempunyai tekanan ke segala arah. Tujuan Penelitian ini untuk mengungkap bahwa karya ilmuan muslim bisa di gunakan sebagai sumber belajar IPA di madrasah agar secara budaya lebih dekat dengan islam. Metode penelitian yang digunakan yaitu metode kualitatif dengan menggunakan pendekatan sejarah filsafat sains berperspektif Islam. Data dikumpulkan melalui studi kepustakaan. Hasil penelitian menunjukkan bahwa Al-Khazini lebih dahulu mengungkapkan mengenai tekanan udara dibandingkan Pascal. Temuan tersebut bisa diajarkan di madrasah melalaui metode demonstrasi yang secara sosiologis antropologis dekat dengan kultur madrasah.
\end{abstract}

Kata Kunci: Filsafat Sains, Tekanan udara, Madrasah. 


\section{Pendahuluan}

Sampai saat ini masih banyak sekolah-sekolah, baik di tingkat Madrasah Tsanawiyyah maupun Madrasah Aliyah yang menggunakan materi pelajaran IPA, khususnya dalam bidang fisika yang bersumber dari pemikiran para ilmuwan barat. Misalnya materi mengenai tekanan yang dikemukakan oleh Blaise Pascal. Padahal ada ilmuan muslim yang sudah lebih dulu mengemukakan konsep tersebut yaitu Al Khazini.

Tujuan dari penelitian ini yaitu agar materi dalam pembelajaran fisika tidak hanya berdasarkan penemuan ilmuwan barat saja namun bisa diselaraskan dengan penemuan ilmuwan-ilmuwan muslim supaya secara kultur lebih dekat dengan islam.

\section{Kerangka Teoretis}

\section{Tekanan Menurut Al-Khazini}

Al Khazini Abu-l-Fath 'Abd al-Rahman al-Mansur al-Khazini (yang dikenal dalam sejarah sains Barat sebagai Al-Khazini) tinggal dan aktif di kota Merv (atau Marw) di wilayah yang sekarang Turkmenistan, menjelang paruh pertama abad XII. Sedikit yang diketahui tentang hidupnya: dia terlahir sebagai budak asal Bizantium dan tuannya adalah seorang bendahara di istana Merv, dia memperhatikan minat budaknya dalam filsafat dan matematika dan memberinya pendidikan yang bagus dalam disiplin ilmu itu.

Buku-buku Al-Khazini ditulis dalam bahasa Arab (bukan dalam bahasa Persia); Yang paling terkenal di antaranya, berjudul Kitab Mizan al-Hikmah atau "The Book of Balance of Wisdom", yang selesai pada tahun 1121 atau 1122 dan menjelaskan ilmu berat dan konstruksi keseimbangan canggih yang sebelumnya telah dijelaskan oleh al-Afizari.

Fokus utama karyanya adalah pada deskripsi Neraca Hikmah atau Balance of Wisdom; Ini adalah keseimbangan hidrostatik dari lima piring, yang mencakup sekitar dua meter (Gambar 1). Karena panjang dan desainnya, neraca ini memiliki ketelitian yang baik dan juga sangat presisi. Al-Khazini memasukkan sebuah tabel yang menunjukkan stabilitas keseimbangan untuk posisi yang berbeda dari titik suspensi. Karena 


\section{Pendekatan Budaya Islam di Madrasah...}

kompleksitas lengan membentuk keseimbangan, penulis memasukkan tabel tindakan yang perlu diambil oleh pengguna agar mendapatkan keseimbangan tergantung pada berbagai posisi di mana instrumen tersebut dapat diberikan.

Situasi keseimbangan yang canggih ini diperbaiki secara teoritis dan juga dengan prosedur trial and error. Keseimbangan ini digunakan tidak hanya untuk membandingkan berat, tapi juga untuk mengevaluasi kandungan logam berbeda (seperti emas dan perak) dalam satu objek (seperti mahkota raja). Aplikasi lain termasuk mengevaluasi berat yang sangat spesifik sekitar 50 zat. ${ }^{1}$

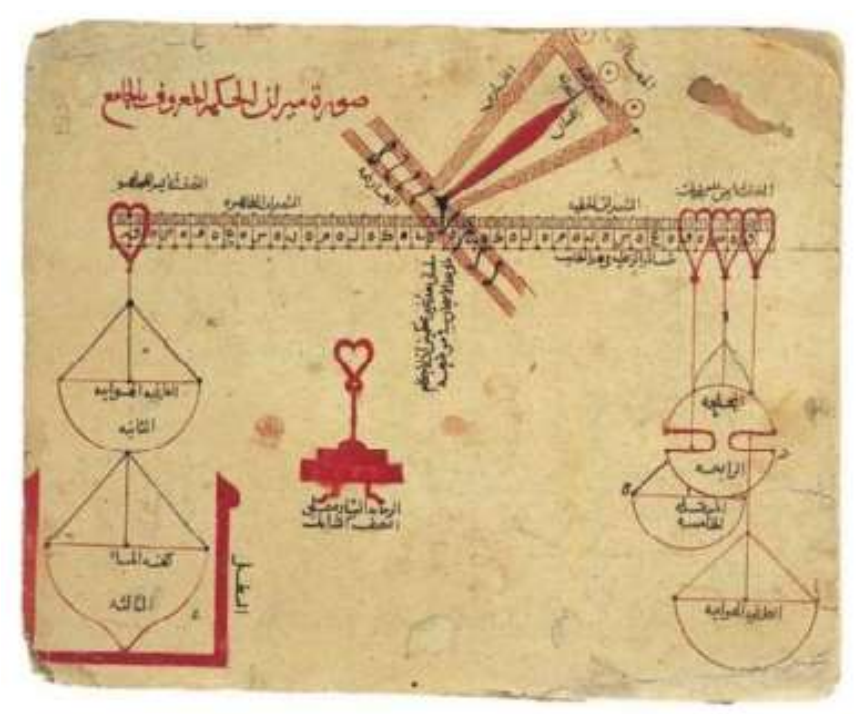

Gambar 1. Balance Of Wisdom [Dari: al-Khazini, The Book of Balance of Wisdom $]^{2}$

1 Luis A. Godoy, "Structural Stability Concepts in Medieval and Renaissance Mechanics," Latin American Journal of Solids and Structures 8 (2011): 83- 105.

2 The Chevalier N. Khanikoff, "Analysis and Extracts of The Balance of Wisdom an Arabic Work on the Water-Balance" (Persia: Russian Consul-General At Tabriz 1857), diakses pada 10 Juni, 2017, https://upload.wikimedia.org/wikipedia/commons/0/0e/Khazini\%2C_Book_of_the_Balance _of_Wisdom_\%28Eng\%29.pdf. 
Berdasarkan Neraca Hikmah Al Khazini, ditemukan bahwasannya udara mempunyai berat dan juga gaya dorong ke atas sehingga udara mempunyai tekanan, sama halnya dengan zat cair. Hal ini menyebabkan udara mempunyai tekanan ke segala arah karena memiliki berat; fakta inilah yang kemudian disebut sebagai tekanan udara. ${ }^{3}$

\section{Materi Pembelajaran Tekanan Udara di Madrasah}

Pembahasan mengenai tekanan udara terdapat dalam materi tekanan hidrostatis di Madrasah Aliyah kelas XI. Setiap benda yang terletak pada suatu bidang akan melakukan tekanan pada bidang tersebut. Begitu pula dengan zat cair yang berada di dalam suatu bidang juga melakukan tekanan terhadap dasar bidang itu. Tekanan yang dilakukan zat cair tersebut merupakan tekanan hidrostatik. Tekanan adalah gaya per satuan luas yang bekerja pada arah tegak lurus suatu permukaan. Dengan demikian, rumus tekanan adalah:

$$
P=\frac{F}{A}
$$

Keterangan:

$P=$ Tekanan $\left(\mathrm{N} / m^{2}\right)$

$F=$ Gaya $(\mathrm{N})$

$A=$ Luas permukaan bidang tekan $\left(\mathrm{m}^{2}\right)$

Gaya berat fluida $F=W=m . g$. Jika $m=\rho . V$ maka $W=\rho . V \cdot g$. Tekanan hidrostatik di dasar bejana.

$$
\begin{gathered}
P h=P o+\frac{\rho(A \cdot h) g}{A} \\
P h=P o+\rho \cdot g \cdot h
\end{gathered}
$$

Po menyatakan tekanan atmosfer di permukaan fluida.

Po $=1$ atmosfer $(1 \mathrm{~atm})=76 \mathrm{~cm} \mathrm{Hg}=105 \mathrm{~N} / \mathrm{m} 2$.

3 Zulfan Afdhilla. "Biografi Al-Khazini (Pencetus Teori Gravitasi \& Penemu Tekanan Udara).” diakses 10 Juni, 2017. http://www.zulfanafdhilla.com/2014/06/Al-Khazini.html. 
Jika tekanan atmosfer di permukaan fluida diabaikan maka tekanan hidrostatik di dasar bejana adalah:

$$
P h=\rho \cdot g \cdot h
$$

Keterangan:

$P h:$ tekanan hidrostatik $(\mathrm{N} / \mathrm{m} 2)$

$\rho:$ massa jenis fluida $(\mathrm{kg} / \mathrm{m} 3)$

$g:$ percepatan gravitasi $(\mathrm{m} / \mathrm{s} 2)$

$h:$ tinggi $(\mathrm{m})$

Berdasarkan persamaan tersebut maka tekanan hidrostatik dipengaruhi oleh massa jenis fluida ( $\rho$ ), percepatan gravitasi (g) dan kedalaman zat cair diukur di permukaan (h). Tekanan hidrostatik tidak dipengaruhi oleh bentuk bejana. Dengan demikian tiap titik konversi satuan tekanan adalah: $1 \mathrm{~atm}=76 \mathrm{~cm} \mathrm{Hg}$ dan $1 \mathrm{~atm}=105 \mathrm{~N} / \mathrm{m} 2=106$ dyne $/ \mathrm{cm} 2.4$

Seorang ilmuwan dari Perancis, Blaise Pascal (1623-1662) telah menyumbangkan sifat fluida statis yang kemudian dikenal sebagai hukum Pascal. Bunyi hukum Pascal itu secara konsep dapat dijelaskan sebagai berikut.

"Jika suatu fluida diberikan tekanan pada suatu tempat maka tekanan itu akan diteruskan ke segala arah sama besar."

Dari hukum Pascal tersebut dapat ditentukan perumusan untuk bejana berhubungan pada Gambar 2 seperti berikut. ${ }^{5}$

${ }^{4}$ Siswanto, Sukaryadi, Kompetensi Fisika : Untuk SMA/MA Kelas XI (Jakarta: Pusat Perbukuan Departemen Pendidikan Nasional, 2009). 157.

${ }^{5}$ Sri Handyani, Fisika 2 : Untuk SMA/MA Kelas XI (Jakarta: Pusat Perbukuan Departemen Pendidikan Nasional, 2009). 112. 


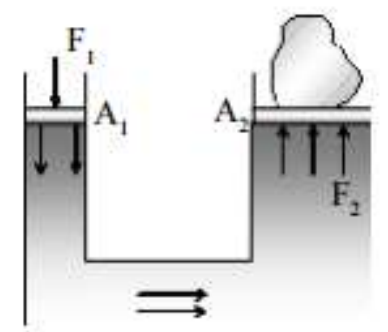

Gambar 2. Bejana Berhubungan

$$
\begin{gathered}
P_{a}=P_{R} \\
\frac{F_{1}}{A_{1}}=\frac{F_{2}}{A_{2}}
\end{gathered}
$$

\section{Metode dan Hasil Penelitian}

Penelitian ini menggunakan metode kualitatif dengan pendekatan sejarah filsafat sains berperspektif Islam. Data dikumpulkan melalui studi kepustakaan.

Menurut Al-Khazini, tekanan udara disebabkan karena udara mempunyai berat dan memiliki gaya dorong keatas, sehingga udara mempunyai tekanan ke segala arah. Pascal menyatakan bahwa "Jika suatu fluida diberikan tekanan pada suatu tempat maka tekanan itu akan diteruskan ke segala arah sama besar". Terdapat kesamaan diantara konsep Al-Khazini dan pernyataan Pascal tersebut, dimana Al-Khazini menyebutkan konsepnya mengenai tekanan udara, sedangkan Pascal menyebutkan mengenai tekanan fluida. Sebagaimana yang kita ketahui udara merupakan salah satu jenis fluida atau zat yang dapat mengalir.

Dalam Hukum Pascal tekanan fluida sudah dinyatakan dalam bentuk persamaan matematis yang lebih sederhana, sementara Al-Khazini membuktikan adanya tekanan udara melalui pembuktian dengan menggunakan Neraca Hikmah, yang karena ukuran dan bentuknya dinyatakan memiliki ketelitian yang baik dan juga presisi. Jadi meskipun tidak dinyatakan langsung dalam persamaan matematis, konsep tekanan udara Al-Khazini sangat layak untuk di sampaikan pada pelaksanaan pembelajaran untuk menunjang materi tekanan pada mata pelajaran fisika di 
madrasah. Selama ini buku penunjang pembelajaran fisika di madrasah cenderung menyatakan secara langsung adanya tekanan udara beserta nilainya, tanpa adanya penjelasan lebih rinci mengenai hal itu. Sehingga siswa kurang memahami dengan baik maksud dari tekanan udara dan asal munculnya tekanan udara tersebut.

Pemahaman mengenai konsep tekanan Al-Khazini selain untuk mengenalkan ilmuwan muslim serta karyanya juga membantu siswa agar dapat memiliki pemahaman yang lebih baik.

\section{Penutup}

Berdasarkan hasil penelitian dan pembahasan dapat disimpulkan bahwa materi mengenai tekanan udara ternyata lebih dulu diungkapkan oleh Al-Khazini, barulah kemudian diungkapkan oleh B laise Pascal dan substansinya pun sama. Oleh karena itu, alangkah lebih baik jika dalam pembelajaran fisika materi tekanan, konsep tekanan udara menurut $\mathrm{Al}$ Khazini juga diperkenalkan dan disampaikan kepada siswa madrasah.

Guru-guru di madrasah diharapkan bisa memperkenalkan ilmuwan muslim lainnya dalam setiap pembelajaran, tidak hanya Al-Khazini dengan konsep tekanan udaranya saja. Masih banyak ilmuwan muslim dengan teori dan konsep hebat lainnya yang bisa dijadikan sebagai dasar dalam penyampaian materi pembelajaran fisika di madrasah, bahkan mungkin pada mata pelajaran yang lainnya. 


\section{Daftar Pustaka}

Afdhilla, Zulfan. Biografi Al-Khazini (Pencetus Teori Gravitasi \& Penemu Tekanan Udara).

Juni 2014. http://www.zulfanafdhilla.com/2014/06/Al-Khazini.html (diakses Juni 10, 2017).

Godoy, Luis A. "Structural Stability Concepts in Medieval and Renaissance Mechanics ." Latin American Journal of Solids and Structures, 2011: 83105.

Handyani, Sri . Fisika 2 : Untuk SMA/MA Kelas XI. Jakarta: Pusat Perbukuan Departemen Pendidikan Nasional, 2009.

Khanikoff, The Chevalier N. "Analysis and Extracts of The Balance of Wisdom an Arabic Work on the Water-Balance." Wikipedia. t.thn. https://upload.wikimedia.org/wikipedia/commons/0/0e/Khazini\%2C _Book_of_the_Balance_of_Wisdom_\%28Eng\%29.pdf (diakses Juni 10, 2017).

Siwanto, dan Sukaryadi. Kompetensi Fisika : Untuk SMA/MA Kelas XI. Jakarta: Pusat Perbukuan Departemen Pendidikan Nasional, 2009. 